\title{
Dietary intake and food sources in the very old
}

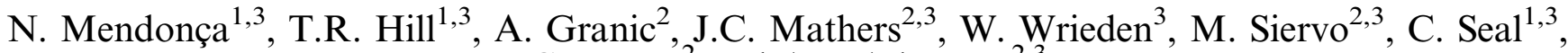 \\ C. Jagger ${ }^{2}$ and A.J. Adamson ${ }^{2,3}$ \\ ${ }^{1}$ School of Agriculture Food and Rural Development, ${ }^{2}$ Newcastle University Institute for Ageing and ${ }^{3}$ Human Nutrition \\ Research Centre, Newcastle University, NE1 7RU, Newcastle upon Tyne, UK
}

Nutrition studies often overlook very old adults ( 85 years and older), resulting in a lack of dietary data of one of the fastest growing age segments of western societies. We aimed to assess dietary intake and respective food sources in 793 eighty-five year-olds (302 men and 491 women) living in North-East England and participating in the Newcastle $85+$ cohort study $^{(1)}$. Details on the Newcastle $85+$ cohort study can be found at http://research.ncl.ac.uk/85plus.

Dietary information was collected at baseline in 2006/2007 using repeated multiple pass 24-hour recall $(2 \times 24 \mathrm{hr}-$ recall). Energy, macronutrient and non-starch polysaccharides (NSP) intakes were estimated using the McCance and Widdowson's Composition of Foods $6^{\text {th }}$ edition. Percentage contribution (\%) to dietary intake was estimated based on 15 food groups: cereals and cereal products, milk and milk products, eggs and egg dishes, oils and fat spreads, meat and meat products, fish and fish dishes, vegetables, potatoes, savoury snacks, nuts and seeds, fruit, sugar, preserves and confectionery, non-alcoholic beverages, alcoholic beverages and miscellaneous.

\begin{tabular}{|c|c|c|c|c|}
\hline Macronutrients & Median (\%) & IQR & $\%$ Compliance with DRV & Top Food Group Contributor ( $\%)$ \\
\hline Energy $(\mathrm{KJ})^{*}$ & 6646 & $5489-8156$ & $19 \cdot 8^{\dagger}$ & cereals and cereal products (34) \\
\hline Carbohydrate $(\mathrm{g})$ & $194(46 \cdot 8)$ & $157-238$ & $33 \cdot 0$ & cereals and cereal products (48) \\
\hline NMES $(g)$ & $42 \cdot 7(10 \cdot 1)$ & $25 \cdot 4-63 \cdot 8$ & $56 \cdot 5$ & cereals and cereal products (32) \\
\hline NSP (g) & $10 \cdot 2$ & $7 \cdot 3-13 \cdot 7$ & $9 \cdot 0$ & cereals and cereal products (42) \\
\hline Total Fat (g) & $65 \cdot 8(36 \cdot 8)$ & $50 \cdot 1-84 \cdot 2$ & $41 \cdot 1$ & cereals and cereal products (23) \\
\hline SFA (g) & $24 \cdot 3(13 \cdot 6)$ & $17 \cdot 3-32 \cdot 4$ & $27 \cdot 9$ & oils and fat spreads (22) \\
\hline MUFA (g) & $15.5(8 \cdot 8)$ & $11 \cdot 1-21 \cdot 3$ & 8.7 & meat and meat products (33) \\
\hline PUFA (g) & $6 \cdot 3(3 \cdot 4)$ & $3 \cdot 9-9 \cdot 9$ & $13 \cdot 7$ & oils and fat spreads (32) \\
\hline Protein $(\mathrm{g})$ & $61 \cdot 3(15 \cdot 7)$ & $48 \cdot 9-75 \cdot 7$ & $76 \cdot 2$ & meat and meat products $(35)$ \\
\hline Protein $(\mathrm{g} / \mathrm{Kg})$ & $0 \cdot 99$ & $0 \cdot 77-1 \cdot 24$ & $71 \cdot 5$ & - \\
\hline
\end{tabular}

NMES, non-milk extrinsic sugars. NSP, non-starch polysaccharides. SFA, saturated fatty acids. MUFA, monounsaturated fatty acids. PUFA, polyunsaturated fatty acids. IQR, Interquartile Range. DRV, Dietary reference values. DRVs are from COMA, 1991 unless otherwise stated * Does not include energy from alcohol. + SACN, 2010

Median energy, NSP, saturated (SFA), monounsaturated and polyunsaturated fatty acids intake failed to meet the current dietary reference values (DRV). However, median protein intake was well above the recommended $0.75 \mathrm{~g} / \mathrm{Kg}$ per day or $53.5 \mathrm{~g}$ for men and $46.5 \mathrm{~g}$ for women ${ }^{(2)}$. Cereals and cereal products were widely consumed and therefore were the top food group contributor for most nutrients, followed by meat and meat products. Although notable, the health significance of the relatively high SFA intake in this age group is yet unknown. However, the low NSP intake is likely to contribute to higher prevalence of constipation in older people.

1. Collerton J, Davies K, Jagger C et al. (2009) Health and disease in 85 year olds: baseline findings from the Newcastle $85+$ cohort study. BMJ 339, b4904.

2. Department of Health, Committee on Medical Aspects of Food Policy (COMA) (1991) Report on Health and Social Subjects 41. Dietary Reference Values for Food Energy and Nutrients for the UK. London:TSO. 